\title{
РОЛЬ ОРГАНОВ МЕСТНОГО САМОУПРАВЛЕНИЯ В ЗАЩИТЕ ПРАВ И СВОБОД ЧЕЛОВЕКА
}

Аннотация. Предметом исследования выступают нормы муниципального законодательства федерального, регионального и местного уровней, регулирующие деятельность органов местного самоуправления по защите прав и свобод человека и гражданина. Исследуется деятельность органов местного самоуправления по защите прав и свобод человека, осуществляемая посредством специфических методов, процедур и средств. На местном уровне создаются необходимые условия для реализации конституционных прав и свобод граждан, что позволяет населению муниципального образования самостоятельно решать вопросы местного значения. В статье также анализируются полномочия органов местного самоуправления по реализации и защите прав и свобод граждан, а также их права и обязанности в указанной сфере. Методология исследования представлена общенаучными и частнонаучными методами, такими как анализ, дедуктивный, диалектический, логический, формально-юридический методы. Новизна исследования заключается в рассмотрении органов местного самоуправления в качестве субъектов, обеспечивающих защиту прав и свобод граждан. Автором делается вывод о социально-значимом характере деятельности муниципальных органов власти по защите прав и свобод человека. Обосновывается необходимость включения органов местного самоуправления в систему органов защиты прав и свобод человека и гражданина, закрепленную в ст. 2 Конституции РФ. Ключевые слова: органы местного самоуправления, защита прав человека, территориальное общественное самоуправление, муниципальный контроль, вопросы местного значения, муниципальное образование, демократия, муниципальная власть, права человека, обращения граждан

Abstract. The research subject is the provisions of municipal legislation of the federal, regional and local levels, regulating the activities of local government bodies, aimed at the protection of human rights and freedoms. The author studies the work of local government bodies in the sphere of the protection of human rights and freedoms, performed with the help of specific methods, procedures and means. Special conditions are created on the local level, necessary for the implementation of constitutional rights and freedoms of citizens. It helps the population of the municipal entity solve local problems independently. The article analyzes the authorities of local government bodies in the implementation and protection of rights and freedoms of citizens, and their rights and responsibilities in this sphere. The research methodology includes general scientific and specific methods, including analysis, the deductive, logical and formal-legal methods. The scientific novelty consists in the consideration of local government bodies as the subjects, protecting rights and freedoms of citizens. The author concludes about the socially important character of activities of local government bodies, aimed at the protection of citizens' rights and freedoms. The author substantiates the necessity to include local government bodies in the system of agencies, protecting human rights and freedoms, enshrined in the article 2 of the Constitution of the Russian Federation.

Key words: democracy, municipal entity, local problems, municipal control, territorial public self-government, human rights protection, local government bodies, local government, human rights, citizens' appeals.

3 акрепляя положения о защите прав и свобод человека и гражданина, Конституция РФ в ст. 130-133 [1] не устанавливает обязанности местного самоуправления по обеспечению и защите прав и свобод человека и гражданина, однако устанавливает, что они определяют деятельность местного самоуправления. На международном уровне защита прав человека также не отнесена к сфере компетенции органов местного самоуправления [2].

Вместе с тем нельзя полностью исключать органы местного самоуправления из числа субъектов, обеспечивающих защиту прав и свобод, поскольку среди основных направлений деятельности органов местного самоуправления по решению вопросов местного значения особое место отво- 


\section{Административное и муниципальное право 12 (108) 2016}

дится функции защиты прав и интересов населения муниципального образования, с реализацией которой связывают все иные функции местного самоуправления. Так, Н.С. Бондарь справедливо отмечает: «местное самоуправление и его органы представляют особый негосударственный уровень единой конституционной системы обеспечения и защиты основных прав и свобод человека и гражданина в Российской Федерации» [3, с. 52].

Защита прав и свобод человека связана с деятельностью органов местного самоуправления, осуществляемой в случае нарушения субъективных прав, т.е. предполагает меры по восстановлению нарушенного права. В этой связи Д.М. Чечот определяет защиту как «принудительный (в отношении обязанного лица) способ осуществления субъективного права, применяемый в установленном законом порядке компетентными органами либо самим управомоченным лицом в целях восстановления нарушенного права» [4].

Применительно к деятельности муниципальных органов власти целесообразно рассматривать защиту с позиций Н.В. Витрука: «деятельность, направленная на устранение препятствий в осуществлении прав и свобод и на борьбу со злоупотреблением правом» [5, с. 203].

Местное самоуправление является важнейшим элементом любого демократического государства. Будучи особой формой осуществления публичной власти народа, которая определяет субъективные права граждан на участие в управлении публичными делами, связанными с удовлетворением основных жизненных потребностей и формированием комфортной биосоциальной среды по месту жительства, местное самоуправление позволяет решить целый комплекс государственно значимых задач [6, с. 144]. Очевидно, что права и свободы гражданина реализуются, прежде всего, на местном уровне, там, где он живет, осуществляет трудовую, политическую и иную деятельность. Поэтому их защита во многом зависит от деятельности органов местного самоуправления.

Местный уровень власти предполагает максимальную приближенность органов муниципального управления к населению, что определяет безусловный приоритет для граждан при выборе той структуры, куда они обратятся за помощью в случае нарушения их прав.

Обязанность органов местного самоуправления защищать прав и свободы человека и гражданина закрепляется, как правило, в муниципально-правовых актах. Так, например, п. 2 ст. 9 Устава муниципального образования «Город Саратов», утвержденного Решением Саратовской городской Думы от 18 декабря 2005 г. № 67-649, органы местного самоуправления обязаны принимать пред- усмотренные действующим законодательством меры по защите прав населения.

Органы местного самоуправления объективно заинтересованы в реальной защите прав граждан, которая обеспечивается деятельностью органов местного самоуправления по решению вопросов местного значения - вопросов непосредственного обеспечения жизнедеятельности населения муниципального образования, перечень которых содержится в ст.ст. 14-17 Федерального закона от 06 октября 2003 г. № 131-ФЗ «Об общих принципах организации местного самоуправления в Российской Федерации» (далее - Ф3 № 131) [7]. Однако в указанных нормах вопросы защиты прав и свобод человека и гражданина не отнесены законодателем к вопросам местного значения. Вместе с тем вопросы непосредственного жизнеобеспечения в основном связаны с оказанием или организацией оказания социальных услуг конкретному гражданину или группе граждан, проживающих в соответствующем муниципальном образовании, а, следовательно, направлены на обеспечение и защиту прав и свобод человека и гражданина.

В Постановлении от 2 апреля 2002 г. № 7-П «По делу о проверке конституционности отдельных положений Закона Красноярского края «0 порядке отзыва депутата представительного органа местного самоуправления» и Закона Корякского автономного округа «0 порядке отзыва депутата представительного органа местного самоуправления, выборного должностного лица местного самоуправления в Корякском автономном округе» в связи с жалобами заявителей А.Г. Злобина и Ю.А. Хнаева» [8] Конституционный Суд РФ констатировал, что субъектом права на самостоятельное осуществление муниципальной власти - непосредственно и через органы местного самоуправления выступает население муниципального образования. Оно вправе защищать свои права и свободы, реализуемые на уровне местного самоуправления, в том числе путем воздействия в различных не противоречащих закону формах на выборных должностных лиц местного самоуправления. Контроль населения за их деятельностью, устанавливаемый в качестве предпосылки соответствующего воздействия, представляет собой, по существу, одно из средств самоорганизации населения.

Местное самоуправление, в отличие от государственной власти, призвано обеспечивать самостоятельное решение населением вопросов местного значения, что осуществляется с помощью эффективно функционирующих демократических институтов, выражающих интересы и волю населения муниципального образования. Это предполагает развитие демократии на местном уровне, поддержку инициатив и самодеятельности граж- 
дан, развитие различных форм самоуправления, создание условий для самостоятельного решения населением вопросов местного значения.

Основными институтами местного самоуправления являются:

1. прямое волеизъявление граждан в решении вопросов местного значения;

2) органы и должностные лица местного самоуправления;

3) территориальное общественное самоуправление (ТОС).

Непосредственное решение населением вопросов местного значения осуществляется посредством участия в местных референдумах, муниципальных выборах, а также посредством иных форм прямого волеизъявления: голосования по отзыву депутата, члена выборного органа местного самоуправления, выборного должностного лица местного самоуправления, голосования по вопросам изменения границ муниципального образования, преобразования муниципального образования, схода граждан, правотворческой инициативы, территориального общественного самоуправления, публичных слушаний, собрания, конференции граждан, опроса граждан, обращения в органы местного самоуправления и др.

Относительно распространенной формой участия населения в осуществлении местного самоуправления является территориальное общественное самоуправление (ст. 27 ФЗ № 131), основополагающим началом которого выступает принцип гарантии и защиты прав и законных интересов населения. Реализация данного принципа осуществляется через представление и защиту интересов жителей своей территории в органах местного самоуправления и в органах государственной власти, обращения в конституционные (уставные) суды, суды общей юрисдикции, арбитражные суды, антимонопольные органы, прокуратуру и иные органы власти. В соответствии с Положением Саратовской городской Думы от 28 июля 2006 г. «0 территориальном общественном самоуправлении в городе Саратове» к полномочиям органов ТОС относится также осуществление мер по социальной поддержке и защите граждан, нуждающихся в общественной поддержке, дополнительно к той, которая предоставляется муниципальными и государственными учреждениями социального обслуживания в пределах имеющихся финансовых средств.

Из всех предусмотренных законом форм участия граждан в решении вопросов местного значения именно у ТОС есть все шансы стать не только инструментом повышения конструктивной активности населения или площадкой для реализации гражданских инициатив, но и эффективным и оперативным механизмом защиты прав граждан.
В целом ответственность за обеспечение и защиту конституционных прав и свобод возложена на государство, а соответствующие функции по обеспечению и защите прав человека - на органы местного самоуправления, которые посредством присущих их специфике методов, процедур и средств должны плодотворно содействовать государству в исполнении возложенной на него конституционной обязанности по обеспечению и защите прав человека.

Так, основными формами правообеспечительной деятельности органов местного самоуправления являются издание ненормативных и индивидуальных правовых актов; осуществление общественно-организационных действий или деятельности организационно-инструктивного характера; выполнение материально-технических действий и т.д. При этом органы местного самоуправления заключают гражданско-правовые договора, представляют обязательные отчеты, применяют средства непосредственного принуждения, участвуют в качестве истцов или ответчиков в судах, применяют многочисленные и разнообразные общеобязательные правила, устанавливаемые центральными и местными органами власти, применяют различные экономические санкции, меры административного принуждения к нарушителям юридических запретов отраслевого, ведомственного характера, способствуя тем самым защите прав и свобод человека и гражданина.

Защита прав человека органами местного самоуправления предоставляется посредством создания необходимых условий для реализации конституционных прав и свобод граждан на местном уровне. В Конституции РФ указан ряд прав и свобод человека и гражданина, к обеспечению которых в соответствии с конституционными нормами имеют непосредственное отношение органы местного самоуправления, т.е. которые могут быть реализованы гражданами на местном уровне. Следовательно, защита таких прав входит в решение вопросов местного значения.

Обеспечение реализации конституционных прав граждан на осуществление местного самоуправления предполагает:

а) создание условий для реализации конституционных прав граждан, прежде всего, прав избирать и быть избранными в органы местного самоуправления; осуществлять местное самоуправление через выборные и иные органы местного самоуправления; участвовать в решении вопросов местного значения путем прямого волеизъявления, а также путем организации и деятельности территориального общественного самоуправления;

б) законодательное определение порядка учета мнения населения при изменении границ муниципальных образований; 


\section{Административное и муниципальное право 12 (108) 2016}

в) создание эффективной системы взаимодействия органов местного самоуправления с населением, в том числе: формирование механизмов контроля за эффективностью деятельности органов местного самоуправления со стороны населения; формирование механизмов ответственности органов местного самоуправления и их должностных лиц перед населением; организацию системы разъяснения населению конституционных основ местного самоуправления и государственной политики в области развития местного самоуправления в Российской Федерации.

В целях реализации конституционных прав и свобод человека и гражданина должностные лица органов местного самоуправления не вправе препятствовать обращению лица с заявлением или жалобой в органы государственной власти и органы местного самоуправления, международные организации, осуществляющие защиту прав человека, а также в национальные и международные общественные организации и средства массовой информации.

В соответствии со ст. 32 Федерального закона «Об общих принципах организации местного самоуправления в Российской Федерации» обращения граждан являются формой несудебной защиты прав человека при обращении граждан в орган местного самоуправления с заявлением, жалобой, предложением или ходатайством.

Обращения граждан, являющиеся необходимым элементом обратной связи между гражданами и формируемыми ими органами местного самоуправления, требуют повышенной ответственности должностных лиц и результативности работы органов местного самоуправления по соблюдению и защите прав и свобод человека и гражданина.

Следует согласиться с Е.С. Шугриной, что «возможность заинтересованного лица обжаловать принятые органами местного самоуправления и их должностными лицами решения, включая нормативные правовые акты, воплощающая в себе как индивидуальный (частный) интерес, связанный с восстановлением нарушенных прав, так и публичный интерес, направленный на поддержание законности и конституционного правопорядка, является неотъемлемой характеристикой нормативного содержания права каждого на судебную защиту, одной из необходимых и важнейших его составляющих» [9, с. 847].

Право граждан избирать и быть избранными в орган местного самоуправления способствует участию населения в управлении делами муниципальных образований, а, следовательно, посредством такого участия граждане получают возможность защищать свои права и права других лиц. Все граждане, достигшие возраста 18 лет, вправе избирать и быть избранными в представительные органы местного самоуправления. Главой исполнительнораспорядительной власти муниципального образования может быть избран гражданин, которому исполнился на день выборов 21 год.

В соответствии с Федеральным законом «Об общих принципах организации местного самоуправления» к полномочиям органов местного самоуправления по реализации и защите социально-экономических и культурных прав и свобод граждан на местном уровне относятся:

а) создание условий для оказания медицинской помощи населению на территории муниципального образования в соответствии с территориальной программой государственных гарантий оказания гражданам РФ бесплатной медицинской помощи и осуществление мероприятий по обеспечению безопасности людей на водных объектах, охране их жизни и здоровья. Органы местного самоуправления не создают специальные исполнительные органы в сфере охраны здоровья и реализуют свои полномочия через муниципальные учреждения;

б) обеспечение условий для осуществления гражданами права на жилище.

В целях защиты прав граждан в жилищной сфере существенно усилена роль органов местного самоуправления в осуществлении контрольных функций за деятельностью управляющих организаций. Муниципальные органы вправе инициировать проведение проверки деятельности управляющих организаций в порядке, установленном уполномоченным федеральным органом исполнительной власти, а также выступать с инициативой внеочередного проведения общего собрания собственников помещений с повесткой о расторжении договора управления.

в) предоставление образования в муниципальном образовательном учреждении. В связи с тем, что муниципальные органы сельских поселений не обладают полномочиями в сфере образования, следовательно, защита прав населения соответствующего муниципального образования в установленной сфере следует признать неэффективной.

Защита прав граждан реализуется недопустимостью применения нормативных актов, затрагивающих права, свободы и обязанности человека и гражданина, если они не были опубликованы в установленном законодательством порядке, что предполагает открытость местного правотворчества и обязательность доведения до сведения граждан всех правовых актов.

Развитие законодательства органами местного самоуправления с целью совершенствования 
защиты прав и свобод человека признано стратегическим национальным приоритетом для противодействия угрозам качеству жизни граждан.

Свободное получение информации о деятельности органов местного самоуправления - важная составляющая процесса защиты прав граждан на муниципальном уровне.

Информационная политика органов местного самоуправления базируется на следующих принципах:

- $\quad$ приоритетности прав человека и гражданина признание, соблюдение, защита прав человека и гражданина в информационной сфере;

- законности - обеспечение законных прав на информацию всех субъектов информационного воздействия и их равной ответственности перед законом;

- открытости и доступности - организационно-правовой режим деятельности органов местного самоуправления обеспечивает гражданам возможность получать необходимый и достаточный объем информации (сведений) о своей структуре, целях, задачах, финансовых и иных существенных условиях деятельности;

- равенства интересов - в равной степени учитываются интересы всех участников информационной деятельности вне зависимости от их социального статуса, формы собственности, конфессиональной принадлежности, пола, возраста и т.п.;

- социальной ориентации - основные мероприятия информационной политики направляются на обеспечение социальных интересов всех контактных групп;

- комплексности - деятельность по реализации информационной политики представляет собой использование всей совокупности личных средств и форм работы, позволяющих информировать население муниципального образования о различных сферах общественной жизни.

В муниципальных образованиях постоянно проводятся сходы, собрания граждан, на которых присутствуют руководители и специалисты органов местного самоуправления, получая оперативную информацию о проблемах граждан, о нарушениях их прав и свобод и т.д. Такие мероприятия позволяют жителям населенных пунктов, удалённых от райцентра, реализовывать как своё право на получение информации, так и решать наболевшие вопросы непосредственно на месте.

Органы местного самоуправления для защиты прав человека на территории муниципального образования имеют право:

- $\quad$ рассматривать жалобы граждан, а также консультировать их по вопросам защиты их прав;
- $\quad$ обращаться в суды в защиту прав населения муниципального образования.

Органы местного самоуправления вправе участвовать в гражданском процессе в качестве лица, выступающего в защиту прав и интересов граждан муниципальных образований. Формы такого участия закреплены в процессуальном законодательстве и представляют собой подачу иска (заявления), вступление в уже начатый процесс для дачи заключения по гражданскому делу. Органы местного самоуправления до принятия решения судом первой инстанции вступают в дело по своей инициативе или по инициативе лиц, участвующих в деле, в целях осуществления возложенных на них обязанностей и защиты прав, свобод и законных интересов других лиц или интересов муниципальных образований.

В соответствии с ч. 1 ст. 46 ГПК РФ органы местного самоуправления вправе обратиться в суд с заявлением в защиту прав, свобод и законных интересов других лиц по их просьбе либо в защиту прав, свобод и законных интересов неопределенного круга лиц.

Федеральный закон «Об общих принципах организации местного самоуправления» не содержит конкретного перечня случаев, когда органы местного самоуправления могут участвовать в гражданском процессе для защиты прав и интересов граждан, что может свидетельствовать о том, что законодатель целенаправленно ограничивает роль органов местного самоуправления в защите прав человека. Законодательно закреплено лишь участие органов местного самоуправления в защиту прав недееспособных лиц (например, Федеральный закон от 24 апреля 2008 г. № 48-ФЗ «Об опеке и попечительстве» [10]).

Формой обеспечения и защиты прав и свобод человека и гражданина является муниципальный контроль (ст. 17.1 ФЗ № 131). Органы местного самоуправления, уполномоченные на выполнение муниципального контроля, их организационная структура, полномочия, функции, порядок их деятельности, перечень должностных лиц и их полномочий определяются в соответствии с уставом муниципального образования и иным муниципальным правовым актом.

Муниципальный контроль способствует соблюдению и защите прав и свобод человека и гражданина, призван обеспечивать эффективное функционирование государственных и муниципальных органов. Для осуществления контрольной деятельности предусмотрено создание контрольных органов муниципальных образований.

Защита прав граждан при осуществлении муниципального контроля представляет собой при- 


\section{Административное и муниципальное право 12 (108) • 2016}

нятие мер, направленных на обеспечение возможности реализации их прав, законных интересов и гарантий, которые им предоставлены федеральным законодательством, нормативными правовыми актами субъектов РФ и муниципальными правовыми актами.

Органы местного самоуправления, кроме собственно организации контроля, обязаны:

- разрабатывать административные регламенты осуществления муниципального контроля в соответствующих сферах деятельности;

- проводить мониторинг эффективности муниципального контроля в соответствующих сфе- рах деятельности, в том числе в защите прав населения муниципального образования.

Подводя итог рассмотрению роли органов местного самоуправления в защите прав граждан, следует отметить, что подобная деятельность муниципалитетов имеет социально-значимый характер. Следовательно, органы местного самоуправления не должны отказываться от защиты прав и интересов граждан муниципальных образований, используя уже накопленный опыт в данной сфере, и должны быть включены в систему органов защиты прав и свобод человека и гражданина, закрепленную в ст. 2 Конституции РФ.

\section{Библиография:}

1. Конституция Российской Федерации (принята всенародным голосованием 12 дек. 1993 г. с учетом поправок, внесенных Законами РФ о поправках к Конституции РФ от 30 дек. 2008 г. № 6-ФКЗ, от 30 дек. 2008 г. № 7-ФКЗ, от 5 февр. 2014 г. № 2-ФКЗ, от 21 июля 2014 г. № 11-ФКЗ) // СЗ РФ. 2014 . № 30 (ч. 1). Ст. 4202.

2. Европейская хартия местного самоуправления (совершено в Страсбурге 15.10.1985) // СЗ РФ. 1998. № 36. Ст. 4466.

3. Бондарь Н.С. Гражданин и публичная власть: конституционное обеспечение прав и свобод граждан в местном самоуправлении. М., 2004. 325 с.

4. Чечот Д.М. Субъективное право и формы его защиты. Л., 1968. 72 с.

5. Витрук Н.В. Конституционный статус личности в СССР. М., 1980. 256 с.

6. Будаев A.М. Защита народовластия на местном уровне: вопросы теории и судебно практики // Труды Института государства и права Российской академии наук. 2012. № 5. С. 138-163.

7. Об общих принципах организации местного самоуправления в Российской Федерации: Федеральный закон от 06 октября 2003 г. (ред. от 03.07.2016) // СЗ РФ. 2003. № 40. Ст. 3822.

8. По делу о проверке конституционности отдельных положений Закона Красноярского края «О порядке отзыва депутата представительного органа местного самоуправления» и Закона Корякского автономного округа «0 порядке отзыва депутата представительного органа местного самоуправления, выборного должностного лица местного самоуправления в Корякском автономном округе» в связи с жалобами заявителей А.Г. Злобина и Ю.А. Хнаева: Постановление Конституционного Суда РФ от 02 апреля 2002 г. № 7-П // Вестник Конституционного Суда РФ. 2002. № 3.

9. Шугрина Е.C. Понятие и формы защиты права на осуществление местного самоуправления // Lex Russica. 2008. T. LXVII. № 4. C. 839-865

10. Об опеке и попечительстве: Федеральный закон от 24 апреля 2008 г. № 48-ФЗ (ред. от 28.11.2015) // С3 РФ. 2008. № 17. Ст. 1755.

11. Мишунина А.А., Герб Р.В. О практике органов местного самоуправления по нормативно-правовому регулированию вопросов социально-культурной и экономической адаптации иностранных граждан // Право и политика. 2014. № 3. С. 368 - 378. DOI: $10.7256 / 1811-9018.2014 .3 .11163$.

12. Шестак О.И. Стратегическое планирование в Российской Федерации в контексте полномочий органов местного самоуправления // Политика и Общество. 2015. № 5. C. 591-602. DOI: 10.7256/1812-8696.2015.5.15102.

13. Карасев Р.Е. Конституционный Суд РФ: защита прав и свобод человека и гражданина в законодательном процессе // Право и политика. 2013. № 12. С. 1614 - 1617. DOI: 10.7256/1811-9018.2013.12.10391.

14. Петров В.Ю. Создание и историческое развитие Конвенции о защите прав человека и основных свобод // Право и политика. 2013. № 12. C. 1688 - 1693. DOI: 10.7256/1811-9018.2013.12.10213.

15. Каллагов Т.Э. Формирование и развитие муниципальной службы в условиях модернизации местного самоуправления в современной России // Финансовое право и управление. 2014. № 2. C. 32 - 40. DOI: 10.7256/23100508.2014.2.13417.

\section{References (transliterated):}

1. Konstitutsiya Rossiiskoi Federatsii (prinyata vsenarodnym golosovaniem 12 dek. 1993 g. s uchetom popravok, vnesennykh Zakonami RF o popravkakh k Konstitutsii RF ot 30 dek. 2008 g. № 6-FKZ, ot 30 dek. 2008 g. № 7-FKZ, ot 5 fevr. 2014 g. № 2-FKZ, ot 21 iyulya 2014 g. № 11-FKZ) // SZ RF. 2014. № 30 (ch. 1). St. 4202.

2. Evropeiskaya khartiya mestnogo samoupravleniya (soversheno v Strasburge 15.10.1985) // SZ RF. 1998. № 36. St. 4466.

3. Bondar' N.S. Grazhdanin i publichnaya vlast': konstitutsionnoe obespechenie prav i svobod grazhdan v mestnom samoupravlenii. M., 2004. 325 c.

4. Chechot D.M. Sub"ektivnoe pravo i formy ego zashchity. L., 1968. $72 \mathrm{s.}$

5. Vitruk N.V. Konstitutsionnyi status lichnosti v SSSR. M., 1980. 256 s.

6. Budaev A.M. Zashchita narodovlastiya na mestnom urovne: voprosy teorii i sudebno praktiki // Trudy Instituta gosudarstva i prava Rossiiskoi akademii nauk. 2012. № 5. S. 138-163. 
7. Ob obshchikh printsipakh organizatsii mestnogo samoupravleniya v Rossiiskoi Federatsii: Federal'nyi zakon ot 06 oktyabrya 2003 g. (red. ot 03.07.2016) // SZ RF. 2003. № 40. St. 3822.

8. Po delu o proverke konstitutsionnosti otdel'nykh polozhenii Zakona Krasnoyarskogo kraya «0 poryadke otzyva deputata predstavitel'nogo organa mestnogo samoupravleniya» i Zakona Koryakskogo avtonomnogo okruga «0 poryadke otzyva deputata predstavitel'nogo organa mestnogo samoupravleniya, vybornogo dolzhnostnogo litsa mestnogo samoupravleniya v Koryakskom avtonomnom okruge» v svyazi s zhalobami zayavitelei A.G. Zlobina i Yu.A. Khnaeva: Postanovlenie Konstitutsionnogo Suda RF ot 02 aprelya 2002 g. № 7-P // Vestnik Konstitutsionnogo Suda RF. 2002 . № 3.

9. Shugrina E.S. Ponyatie i formy zashchity prava na osushchestvlenie mestnogo samoupravleniya // Lex Russica. 2008. T. LXVII. № 4. S. 839-865

10. Ob opeke i popechitel'stve: Federal'nyi zakon ot 24 aprelya 2008 g. № 48-FZ (red. ot 28.11.2015) // SZ RF. 2008 . № 17. St. 1755.

11. Mishunina A.A., Gerb R.V. O praktike organov mestnogo samoupravleniya po normativno-pravovomu regulirovaniyu voprosov sotsial'no-kul'turnoi i ekonomicheskoi adaptatsii inostrannykh grazhdan // Pravo i politika. 2014. № 3. C. 368 - 378. DOI: 10.7256/1811-9018.2014.3.11163.

12. Shestak O.I. Strategicheskoe planirovanie v Rossiiskoi Federatsii v kontekste polnomochii organov mestnogo samoupravleniya // Politika i Obshchestvo. 2015. № 5. C. 591-602. DOI: 10.7256/1812-8696.2015.5.15102.

13. Karasev R.E. Konstitutsionnyi Sud RF: zashchita prav i svobod cheloveka i grazhdanina v zakonodatel'nom protsesse // Pravo i politika. 2013. № 12. C. 1614 - 1617. DOI: 10.7256/1811-9018.2013.12.10391.

14. Petrov V.Yu. Sozdanie i istoricheskoe razvitie Konventsii o zashchite prav cheloveka i osnovnykh svobod // Pravo i politika. 2013. № 12. C. 1688 - 1693. DOI: 10.7256/1811-9018.2013.12.10213.

15. Kallagov T.E. Formirovanie i razvitie munitsipal'noi sluzhby v usloviyakh modernizatsii mestnogo samoupravleniya $\mathrm{v}$ sovremennoi Rossii // Finansovoe pravo i upravlenie. 2014. № 2. C. 32 - 40. DOI: 10.7256/2310-0508.2014.2.13417. 